\title{
Multi-Objective Energy Management of a Micro-Grid Considering Stochastic Nature of Load and Renewable Energy Resources
}

\author{
Deyaa Ahmed ${ }^{1}$, Mohamed Ebeed ${ }^{2}\left(\mathbb{D}\right.$, Abdelfatah Ali $^{3} \oplus$, Ali S. Alghamdi ${ }^{4, *}$ and Salah Kamel $^{5, * \mathbb{C}}$ \\ 1 Holding Company for Water and Wastewater (HCWW), Aswan 81542, Egypt; deghaly1982@gmail.com \\ 2 Department of Electrical Engineering, Faculty of Engineering, Sohag University, Sohag 82524, Egypt; \\ mebeed@eng.sohag.edu.eg \\ 3 Department of Electrical Engineering, Faculty of Engineering, South Valley University, Qena 83523, Egypt; \\ a.ahmed@eng.svu.edu.eg \\ 4 Department of Electrical Engineering, College of Engineering, Majmaah University, \\ Almajmaah 11952, Saudi Arabia \\ 5 Department of Electrical Engineering, Faculty of Engineering, Aswan University, Aswan 81542, Egypt \\ * Correspondence: aalghamdi@mu.edu.sa (A.S.A.); skamel@aswu.edu.eg (S.K.)
}

check for updates

Citation: Ahmed, D.; Ebeed, M.; Ali, A.; Alghamdi, A.S.; Kamel, S. MultiObjective Energy Management of a Micro-Grid Considering Stochastic Nature of Load and Renewable Energy Resources. Electronics 2021, 10, 403. https://doi.org/10.3390/ electronics10040403

Academic Editors: Majid Astaneh, Andrew McGordon and

Vítor Monteiro

Received: 5 January 2021

Accepted: 26 January 2021

Published: 7 February 2021

Publisher's Note: MDPI stays neutral with regard to jurisdictional claims in published maps and institutional affiliations.

Copyright: (c) 2021 by the authors. Licensee MDPI, Basel, Switzerland. This article is an open access article distributed under the terms and conditions of the Creative Commons Attribution (CC BY) license (https:// creativecommons.org/licenses/by/ $4.0 /)$.

\begin{abstract}
Optimal inclusion of a photovoltaic system and wind energy resources in electrical grids is a strenuous task due to the continuous variation of their output powers and stochastic nature. Thus, it is mandatory to consider the variations of the Renewable energy resources (RERs) for efficient energy management in the electric system. The aim of the paper is to solve the energy management of a micro-grid (MG) connected to the main power system considering the variations of load demand, photovoltaic (PV), and wind turbine (WT) under deterministic and probabilistic conditions. The energy management problem is solved using an efficient algorithm, namely equilibrium optimizer (EO), for a multi-objective function which includes cost minimization, voltage profile improvement, and voltage stability improvement. The simulation results reveal that the optimal installation of a grid-connected PV unit and WT can considerably reduce the total cost and enhance system performance. In addition to that, EO is superior to both whale optimization algorithm (WOA) and sine cosine algorithm (SCA) in terms of the reported objective function.
\end{abstract}

Keywords: energy management; micro-grid; stochastic nature; renewable energy resources; equilibrium optimizer

\section{Introduction}

Load demand is increasing rapidly and the growth of energy will increase by $40 \%$ from 2006 to 2030 [1]. The growing energy demand, the increase in its price, and the increasing pollution worldwide are considered large problems that need unusual solutions. To overcome these problems, it is necessary to search for innovative solutions using renewable resources and energy management of the energy systems. Energy management means reducing the operating, maintenance, and generation costs of the system and enhancing system performance with methods such as power loss reduction and stability enhancement and alleviating the harmful emissions to the environment. Thus, the energy management of a micro-grid has become one of the most vital aspects of the power or energy system all over the world [2]. The optimal energy management of a micro-grid can be accomplished by considering or managing the consumption, load profile, price of energy, energy sources, cost of sources installation, source operation, construction, and optimal installation of the renewable distributed generators (DGs) [3].

The authors in [4] solved the energy management of a microgrid consisting of photovoltaic (PV), wind turbine (WT), and electrical storage system for a multi-objective function that includes the cost of energy, lifecycle cost, and the annual cost of load loss in addition 
to the overall benefit while satisfying the micro-grid (MG)'s constraints. In [5], the energy management of a MG was solved by considering the solar and wind power units' uncertainty. The uncertainty is handled using the Latin hypercube sampling method. In [6], a micro-grid investigation was performed, including multi-type WT generators, including squirrel cage induction generators, double fed induction generator, and full converter wind generation under grid fault. R.M. Kamel and K. Nagasaka in [7] investigated the performance of faults in a micro-grid under dynamic and static load, including static power loads, static impedance loads, and current static load. The WT is used as an energy resource where the main task of this work was to study the influence of the load type on the standalone micro-grid's fault performance. A comprehensive review for hybrid renewable microgrid optimization techniques was given in [8]. This review found that the reliability of the micro-grids increases when the WT and PV are combined with the storage devices. In [9], a multi-objective particle swarm optimization (MOPSO) was employed to optimize the energy management of a micro-grid for cost and emission reductions. M. Motevasel and A.R. Seif applied the modified bacterial foraging optimization (MBFO) for energy management of a micro-gird with the inclusion of a wind-based DG and storage system considering the uncertainty of the wind energy [10]. In [11], a modified bacterial foraging optimization was applied for optimal energy management of a MG for cost and emission reductions, which consisted of WT, distributed energy resources, and energy storage system. The fuzzy self-adaptive particle swarm optimization (FSAPSO) algorithm was proposed and implemented to solve MG's energy management to reduce the operation cost and emission with optimal scheduling multi resources including WT, PV, battery, and fuel cell unit system [12]. In [13], a modified honey bee mating optimization (MHBMO) algorithm was employed for micro-grid energy management to minimize the micro-grid's cost of operation. The efficient salp swarm algorithm (ESSA) was proposed in [14] and applied for reducing the operation cost of a micro-grid connected with renewable energy sources and storage systems. The ant-lion optimizer (ALO) algorithm was employed to minimize the cost of energy production in the presence of renewable resources and storage systems [15]. In [16], the author used moth flame optimization (MFO) to minimize micro-grid power losses. Symbiotic organisms search (SOS) was applied to optimally manage the energy t of the micro-grid in the presence of renewable resources (RESs) [17]. Many other methods have been employed to solve the issues related to the energy management of micro-grids. In [18], the author used the convex method to assist the optimal size of storage battery to minimize the total cost. Another example for these methods was used in [19] for off grid micro-grid where the author used the moth flame optimization algorithm to implement the system and its components' life cycle cost.

Equilibrium optimizer (EO) is a novel physical-based algorithm presented by A. Faramarzi et al. in 2020. EO, which stimulates the dynamic mass equilibrium on a control volume [20], has been applied for solving numerous optimization problems. In [21], the EO was implemented to solve a vehicle seat bracket's structural design. EO was used to solve the optimal power flow problem in an AC/DC power network [22]. The authors in [23] solved the image segmentation problems by applying EO. A.M. Shaheen used the EO for optimizing the configuration of multiple distribution networks [24]. In binary, EO was implemented to optimize the feature selection [25]. In [26], the optimal allocation problem of renewable distributed generators under uncertainties of the system was solved using EO. G. Aghajani and N. Ghadimi solved the energy management problem for a MG to minimize the operation cost and emission using multi-objective particle swarm algorithm [9]. In [27], fuzzy logic grey wolf optimization was applied to solve the energy management problem for a MG in presence of the RERs and energy storage systems. The authors in [28] proposed a day-ahead management system considering both tertiary and primary control layers for cost reduction and power factor improvement. The authors in [29] proposed a threelayered approach for optimizing the distributed optimal resource in multi-agent systems framework. Several efforts have been presented for developing a multi-types of energy storage systems where the authors in [30] proposed a novel design for an inexpensive 
reusable, liquid-cooled, hexagonal battery module to be suitable for mobile and stationary applications. An investigation and a comparison have been performed between of two types electrolytes including traditional salt-in-water and water-in-salt electrolytes for symmetric supercapacitors [31]. The authors in [32] proposed a new method for designing electrodes, manufactured from sustainable resources by hybridizing calcined eggshell capacitor anode. From the literature survey, the research gaps found can be summarized as follows:

- The energy management problem of a MG is nonlinear, nonconvex, and is not an easy task. Thus, selection of an efficient method or optimization technique for solving this problem is a crucial task.

- Most of the presented efforts solved the energy management problem at the deterministic conditions where the uncertainties of the renewable energy resources and the load demands were not considered.

- Due to the intermediacy and continuous variations of RERs' powers leading to increasing uncertainties of system, the energy management problem solution has become more complex and the uncertainties of these resources should be modeled efficiently to be embedded in the energy management problem solution.

- Some papers solved the energy management for enhancing the system performance only and some papers solve the energy management from an economic perspective only. However, very few papers take into consideration the system performance and the economic benefits of RERs simultaneously.

In this paper, the EO technique is employed to solve energy management of a MG by incorporating renewable distributed generators with and without considering the uncertainties of the system. The main contributions of the paper are as follows:

- Solving the energy management of a MG with integration of RERs under deterministic and probabilistic conditions.

- Application of EO technique as one of the most recent algorithms for solving the energy management problem.

- Assigning the optimal ratings and placement of a solar PV unit and WT to enhance the system's performance and reduce the total cost.

- Comparing the performance of the proposed algorithm for solving the reported problem with well-known techniques.

- An investigation is carried out to study the impact of optimization of the energy management of MG with the inclusion of the RERs.

The paper is arranged as follows: Section 2 defines the problem formulation, the system constraints, and the modeling of the RERs. Section 3 describes the methodology of uncertainty modeling. Section 4 describes the procedure of the $\mathrm{EO}$ and its application for solving energy management. The simulation results and the conclusions are listed in Sections 5 and 6, respectively.

\section{Problem Formulation}

In this study, three objective functions are considered in a multi-objective function for energy management of the micro-grid with satisfying the MG constraints, which can be formulated as follows:

\subsection{The Objective Function}

\subsubsection{The Cost Reduction}

The total annual cost is considered, which includes the annual energy loss cost $\left(\mathrm{Co}_{\text {loss }}\right)$, the cost of purchasing electric energy from the main substation $\left(\mathrm{Co}_{\mathrm{Grid}}\right), \mathrm{PV}$ units cost $\left(\mathrm{Co}_{P V}\right)$, and WT cost $\left(\mathrm{Co}_{W T}\right)$, and it can be represented as follows:

$$
\mathrm{Co}=\min \left(\mathrm{Co}_{\text {loss }}+\mathrm{Co}_{\mathrm{Grid}}+\mathrm{Co}_{P V}+\mathrm{Co}_{W T}\right)
$$


The detailed items of Equation (1) are defined as follow:

$$
\begin{aligned}
& C o_{\text {Grid }}=365 \times K_{\text {Grid }} \times \sum_{h=1}^{24} P_{\text {Grid }(h)} \\
& \operatorname{Co}_{\text {Loss }}=365 \times K_{\text {Loss }} \times \sum_{h=1}^{24} P_{\text {Total_loss }(h)} \\
& \operatorname{Co}_{P V}=\operatorname{Cost}_{P V}^{i n s t .}+\operatorname{Cost}_{P V}^{O \& M} \\
& C o_{P V}^{O \& M}=K_{P V}^{O \& M} \times \sum_{h=1}^{24} P_{P V(h)} \\
& C o_{P V}^{\text {inst. }}=C F \times K_{P V} \times P_{s r} \\
& \operatorname{Co}_{W T}=\operatorname{Cost}_{W T}^{\text {inst. }}+\operatorname{Cost}_{W T}^{\mathrm{O} \& M} \\
& C o_{W T}^{O \& M}=K_{P V}^{O \& M} \times \sum_{h=1}^{24} P_{W T(h)} \\
& C o_{W T}^{\text {inst. }}=C F \times K_{W T} \times P_{w r} \\
& C F=\frac{\beta \times\left(1+\beta_{P V, W T}\right)^{N P_{P V, W T}}}{\left(1+\beta_{P V, W T}\right)^{N P_{P V, W T}}-1}
\end{aligned}
$$

where $K_{\text {Grid }}$ is the purchasing energy cost from the grid, $K_{\text {Loss }}$ is the energy loss cost, $K_{P V}^{O \& M}$ is the operation and maintenance costs of the PV unit, $C o_{W T}^{O \& M}$ is the operation and maintenance costs of the wind turbine, $\operatorname{Cost}_{P V}^{i n s t}$ is the installation cost of the PV unit, $\operatorname{Cos} t_{W T}^{\text {inst. }}$ is the installation cost of the WT, $K_{P V}$ is the purchasing cost of the PV unit $(\$ / \mathrm{kW}), K_{W T}$ is the purchasing cost of the WT $(\$ / \mathrm{kW}), \beta_{P V, W T}$ is the interest rate of capital investment of the installed PV or WT, $N P_{P V, W T}$ is the lifetime of the PV unit or the WT, $C F$ the capital recovery factor, $P_{P V}$ is the hourly output power of the PV system, $P_{w r}$ is the rated power of the WT, and $P_{s r}$ is the rated power of the PV unit. The output powers of the PV units and the WT are calculated using (11) and (12) as following [33]:

$$
P_{P V}=\left\{\begin{array}{cl}
P_{s r}\left(\frac{G_{s}{ }^{2}}{G_{s t d} \times X_{c}}\right) & \text { for } 0<G_{s} \leq X_{c} \\
P_{s r}\left(\frac{G_{s}}{G_{s t d}}\right) & \text { for } \quad X_{c} \leq G_{s} \leq G_{S T D} \\
P_{s r} & G_{S T D} \leq G_{s}
\end{array}\right.
$$

where $G_{s}$ denotes the solar irradiance; $G_{s t d}$ represents the standard environment solar irradiance, which equals $1000 \mathrm{~W} / \mathrm{m}^{2} ; X_{c}$ denotes a certain irradiance point, which equals 120 .

$$
P_{W T}(\omega)=\left\{\begin{array}{ccc}
0 & \text { for } & \omega<\omega_{i} \text { and } \omega>\omega_{0} \\
P_{w r}\left(\frac{\omega-\omega_{i}}{\omega_{r}-\omega_{i}}\right) & \text { for } & \left(\omega_{i} \leq \omega \leq \omega_{r}\right) \\
P_{w r} & \text { for } & \left(\omega_{r}<\omega \leq \omega_{0}\right)
\end{array}\right.
$$

where $\omega_{r}$ denotes the rated wind speed; $\omega_{0}$ denotes the cut-out wind speed; $\omega_{i}$ denotes the cut-in wind speed. 


\subsubsection{Voltage Profile Improvement}

The performance of the system can be enhanced by minimizing the voltage deviations, which can be described as follows:

$$
\sum V D=\sum_{h=1}^{24} \sum_{n=1}^{N B}\left|\left(V_{n}-1\right)\right|
$$

where $V_{n}$ is the voltage of the $n^{\text {th }}$ bus; and $N B$ denotes the number of buses in the grid.

\subsubsection{Voltage Stability Enhancement}

The third objective function is stability enhancement, which can be specified by maximizing the voltage stability index (VSI), which can be described as follows [34]:

$$
\begin{gathered}
V S I_{n}=\left|V_{n}\right|^{4}-4\left(P_{n} X_{n m}-Q_{n} R_{n m}\right)^{2}-4\left(P_{n} X_{n m}+Q_{n} R_{n m}\right)\left|V_{n}\right|^{2} \\
\sum V S I=\sum_{h=1}^{24} \sum_{n=1}^{N B} V S I_{n}
\end{gathered}
$$

where $R_{n m}$ and $X_{n m}$ are the resistance and reactance of the transmission line between buses $m$ and $n$, respectively; $P_{n}$ and $Q_{n}$ are the injective active and reactive power, respectively, at bus $n$. The considered objective function is a multi-objective function which can be described as follows:

$$
\begin{gathered}
F=W_{1} F_{1}+W_{2} F_{2}+W_{3} F_{3} \\
F_{1}=\frac{C o_{\text {RERs }}}{C o_{\text {Base }}} \\
F_{2}=\frac{V D_{\text {RERs }}}{V D_{\text {Base }}} \\
f_{3}=\frac{1}{V S I_{\text {RERs }}}
\end{gathered}
$$

RERs subscript denotes the inclusion of RERs to the system, while the Base subscript denotes the base case or without the RERs. The selected values of the $W_{1}, W_{2}$, and $W_{3}$ are $0.5,0.25$, and 0.25 , respectively [35].

\subsection{The System Constraints}

2.2.1. Inequality Constraints

$$
\begin{gathered}
V_{\min } \leq V_{n} \leq V_{\max } \\
P_{s r}+P_{w r} \leq \sum_{i=1}^{N B} P_{D, i} \\
P F_{\min } \leq P F \leq P F_{\text {max }} \\
I_{n} \leq I_{\text {max }, n} n=1,2,3 \ldots, N T
\end{gathered}
$$

where $V_{\min }$ is the minimum limit of the voltage while $V_{\max }$ is the maximum voltage limit. $P_{D}$ and $Q_{D}$ denote the active and reactive demand, respectively; $I_{\max , n}$ is the maximum current at the $\mathrm{n}$-th branch; $P F_{\min }$ and $P F_{\max }$ are the minimum and maximum limits of the WT power factor, respectively; NT denotes the number of TL. 


\subsubsection{Equality Constraint}

$$
\begin{gathered}
P_{S}+P_{P V}+P_{W T}=\sum_{i=1}^{N T} P_{\text {loss }, i}+\sum_{i=1}^{N B} P_{D, i} \\
Q_{S}+P_{W T}=\sum_{i=1}^{N T} Q_{\text {loss }, i}+\sum_{i=1}^{N B} Q_{D, i}
\end{gathered}
$$

where $P_{S}$ and $Q_{S}$ are the active and reactive powers of the mean upstream substation, respectively.

\section{Uncertainty Modeling}

Here, the modeling of the uncertainty for the solar irradiance, wind speed, and load demand is explained. The generation of the probabilistic models for a unit of PV and WT as well as the load demand was based on the hourly historical data of the location under research. Three years of hourly historical data for wind speed, solar irradiance, and load demand have been considered in this work. The three years are represented by a day throughout these years $(24 \mathrm{~h})$. The probability distribution function (pdf) of each time segment can be achieved using the data associated with the same hours of the day. Consequently, each time segment has 1095 solar irradiance, wind speed, and load demand ( 3 years $\times 365$ days per year), generating the equivalent hourly pdfs. The probabilistic model of the PV system, WT, and load demand can be given as follows.

\subsection{Solar Irradiance Modeling}

A beta pdf for each hour was generated by utilizing the solar irradiance data of that hour and can be mathematically described as follows [36,37]:

$$
f_{b}\left(g_{s}\right)= \begin{cases}\frac{\Gamma(\alpha+\beta)}{\Gamma(\alpha) \Gamma(\beta)} s^{(\alpha-1)}\left(1-g_{s}\right)^{(\beta-1)} & 0 \leq g_{s} \leq 1, \alpha, \beta \geq 0 \\ 0 & \text { otherwise }\end{cases}
$$

where $f_{b}\left(g_{s}\right)$ and $\Gamma$ represent the beta pdf of the solar irradiance and the gamma function, respectively; the beta parameters for each period are denoted by $\alpha$ and $\beta$. The historical data can be used to determine these parameters as follows [38,39]:

$$
\begin{gathered}
\beta=(1-\mu) \times\left(\frac{\mu \times(1+\mu)}{\sigma^{2}}-1\right) \\
\alpha=\frac{\mu \times \beta}{1-\mu}
\end{gathered}
$$

where the mean and standard deviation of the solar irradiance for each time segment are denoted by $\mu$ and $\sigma$, respectively. The continuous beta pdfs are split into many segments in which each individual segment creates a mean value and a probability of happening. The probability of happening for a segment during a specific hour can be described by:

$$
\operatorname{prob}_{i}^{g_{s}}=\int_{g_{s, i}}^{g_{s, i+1}} f_{b}\left(g_{s}\right) d g_{s, i}
$$

where the start and endpoints of the interval $i$ are denoted by $g_{s, i}$ and $g_{s, i+1}$, respectively. prob $_{i}^{g_{s}}$ is the probability happening of the interval $i$. Based on the generated beta pdf of the solar irradiance of a time segment, the output power PV for this time period's states can be calculated using (11). 


\subsection{Wind Speed Modeling}

The power generated by a WT depends on the value of the wind speed and the turbine's characteristics. The wind speed is frequently modeled by using Weibull pdf with shape parameter equalling $2[33,40]$, and it is called Rayleigh pdf [41]. Hence, here, the historical data of hourly wind speeds were utilized to create the Rayleigh pdfs $\left(f_{r}^{t}(v)\right)$ for each time segment, which could be computed as follows:

$$
f_{r}(v)=\left(\frac{2 v}{c^{2}}\right) \exp \left[-\left(\frac{v}{c}\right)^{2}\right]
$$

where the wind speed is denoted by $v$, while $c$ is the scale parameter of Rayleigh. Like solar irradiance, the continuous pdfs were split into many segments in which each segment generated a mean value and a probability of happening. Therefore, the probability of each segment could be determined as follows:

$$
\operatorname{prob}_{i}^{v}=\int_{v_{w 1}}^{v_{w 2}} f_{r}(v) \cdot d v_{i}
$$

where the wind speed limits of the segment $i$ denoted by $v_{w 1}$ and $v_{w 2} ; p r o b_{i}^{v}$ denotes the happening probability of state $i$. Based on the WT characteristics, the wind speed can be converted into the wind generation system's output power based on (12).

\subsection{Load Demand Modeling}

Due to the uncertainty of the load demand, a normal pdf is utilized for modeling the demand. The normal pdf of the uncertain load demand can be determined using the following formula [39]:

$$
f_{n}(l)=\frac{1}{\sigma_{l} \sqrt{2 \pi}} \times \exp \left[-\left(\frac{l-\mu_{l}}{2 \sigma_{l}^{2}}\right)\right]
$$

where the normal pdf of the demand is denoted by $f_{n}(l)$; the mean and standard deviation of the load demand are defined, respectively, by $\mu_{l}$ and $\sigma_{l}$. The probability happening of a segment can be described by:

$$
\operatorname{prob}_{i}^{l}=\int_{l_{i}}^{l_{i+1}} f_{n}(l) d l
$$

where the starting and ending points are denoted by $l_{i}$ and $l_{i+1}$ of the interval i. pro $b_{i}^{l}$ is the probability happening of interval $i$.

\subsection{Combined Model of Wind, PV, and Load}

The probabilistic models of the wind speed, solar irradiance and load demand are employed for generating a combined probability model $\left(P_{\text {com }, i}\right)$ of wind-PV-load. The combined model of the interval $I$, each time segment, can be calculated by convolving the probabilities of the wind speed, solar irradiance, and load demand, as follows:

$$
P_{c o m, i}=\operatorname{prob}_{i}^{v} \times \operatorname{prob}_{i}^{g_{s}} \times \operatorname{prob}_{i}^{l}
$$

Each time segment, the objective function given in (1) should be calculated and weighted according to the combined probability model (30). In this work, each time segment was represented by one hour. This implies that, for each time period, each variable had several states. However, for the sake of simplicity, only the expected values of the variables are given. 


\section{Equilibrium Optimizer}

The equilibrium optimizer (EO) is a developed optimization algorithm that mimics the control volume forms' mass balance to assign the dynamic and equilibrium states. In the EO, the concentrations represent the search agents or the optimization algorithm populations where the concentrations update their locations around equilibrium candidates. The mass balanced equation is formulated as follows:

$$
V \frac{d c}{d t}=Q X_{e q}-Q X+G
$$

where $V$ is the control volume, $X$ is the concentration, and $Q$ the flow rate. The integration and manipulating of the Equation (35), it can be represented as follows:

$$
X=X_{e q}+\left(C_{0}-C_{e q}\right) \exp \left[-\lambda\left(t-t_{0}\right)\right]+\frac{G}{\lambda V}\left(1-\left(\exp \left[-\lambda\left(t-t_{0}\right)\right]\right)\right)
$$

where $\lambda=\left(\frac{Q}{V}\right) . X_{0}$ denotes the initial concentration while $t_{0}$ refers to the initial start time. The following steps describe the procedure of the EO:

\section{Step 1: Initialization}

The concentrations are initialized randomly as follows:

$$
X_{i}^{\text {initial }}=X_{\text {min }}+\operatorname{rand}_{i}\left(X_{\max }-X_{\text {min }}\right) i=1,2, \ldots \ldots n
$$

where $X_{\max }$ refers to the maximum limit of the control variables while $X_{\min }$ is the minimum limit. $r a n d_{i}$ is a random variable within [0,1]. Then, evaluate the objective function for each concentration.

Step 2: Assigning the Equilibrium candidates

The populations are sorting and the four best solutions are captured and their average value to form the pool vector $\left(X_{\text {pool }}\right)$ as follows:

$$
\begin{gathered}
X_{\text {avg }}=\frac{X_{1}+X_{2}+X_{3}+X_{4}}{4} \\
X_{\text {pool }}=\left\{X_{1}, X_{2}, X_{3}, X_{4}, X_{a v g}\right\}
\end{gathered}
$$

Step 3: The concentration updating.

Two randomly vectors $(r, \lambda)$ are generated randomly and utilized to adjust an exponential factor $(F)$ for updating the concentrations as follows:

$$
F=a_{1} \operatorname{sign}(r-0.5)\left[e^{-\lambda t}-1\right]
$$

where

$$
t=\left(1-\frac{T}{T_{M a x}}\right)^{\left(a_{2} \frac{T}{T_{M a x}}\right)}
$$

where $a_{1}$ and $a_{2}$ refer to constant terms, which are set to be 2 and 1 , respectively, to adjust the exponential factor. $T_{M a x}$ is the maximum iteration number, and $T$ denotes the $T$-th iteration. It should be indicated here that $a_{1}$ is utilized to controls the exploration phase of the EO and $a_{2}$ is utilized to control the exploitation process of the EO. Sign $(r-0.5)$ controls the direction of the exploration.

Step 4: Concentration updating based on the generation rate.

The generation rate is an efficient method to enhance the exploitation phase of the optimization algorithm as follows:

$$
G=G_{0} e^{-k\left(t-t_{0}\right)}
$$

where,

$$
G_{0}=G C P\left(X_{\text {pool }}-\lambda X\right)
$$




$$
G C P= \begin{cases}0.5 r_{1} & r_{2} \geq G P \\ 0 & r_{2}<G P\end{cases}
$$

where $r_{1}$ and $r_{2}$ are random numbers within the range [0,1]. GP denotes the generation probability to control the participation probability of concentration, which is updated by the generation rate. If $G P=1$ generation rate will not participate in the optimization process. If $G P=0$, the generation rate will participate in the process. $G P=0.5$ provides an excellent balancing between exploitation and exploration phases. Referring to the previous steps, the updated equation of the EO is formulated as follows:

$$
X=X_{\text {pool }}+\left(X-X_{\text {pool }}\right) \cdot F+\frac{G}{\lambda V}(1-F)
$$

Step 5: Adding memory saving.

In this step, the obtained concentration is compared with the previous concentration, and it will be accepted if this value is enhanced. Figure 1 shows the flow chart of optimal energy management.
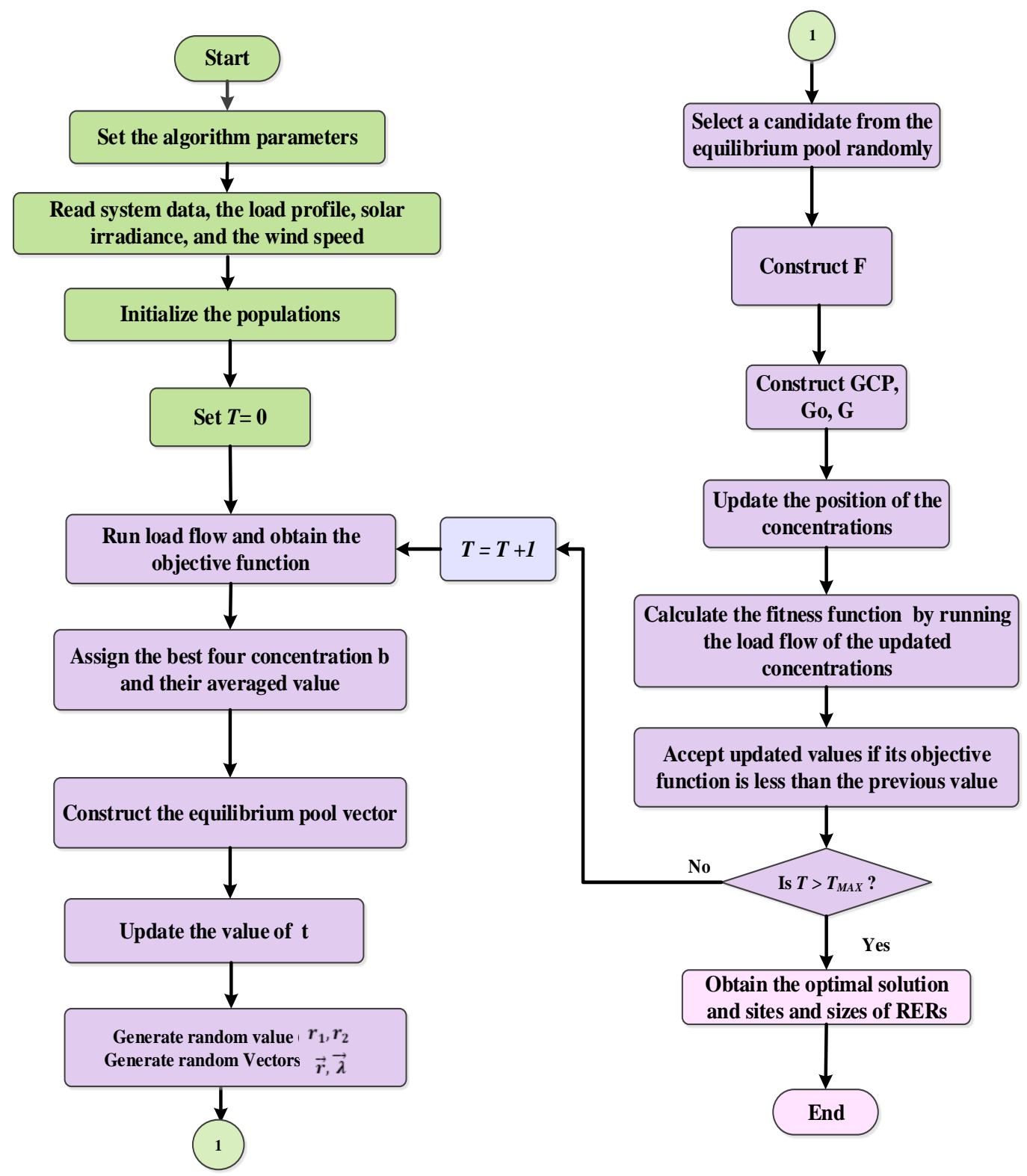

Figure 1. Flow chart for application of the equilibrium optimizer (EO) for optimal energy management. 


\section{Simulation Results}

In this section, the proposed $\mathrm{EO}$ algorithm is applied to solve the energy management of the micro-grid and optimize the sizing and location of the renewable-based DGs, including PV and WT, with and without considering the uncertainty. The captured results are then compared with whale optimization algorithm (WOA) and sine cosine algorithm (SCA) techniques for verifying the effectiveness of the proposed method. The proposed algorithm is applied to the 12-bus system, and its single is depicted in Figure 2. The bus and line data are listed in Appendix A. The system specifications and the initial load flow at $100 \%$ loading are shown in Table 1 . The proposed method for optimal energy management was written in MATLAB software (MATLAB 2014) on $2.5 \mathrm{GHz}$ core I5 with 4 GB PC. The cost coefficients and the system constraints are tabulated in Table 2. The EO, WOA, and SCA selected parameters for all studied cases are listed in Table 3. Two studied cases are presented for the energy management with and without considering the uncertainties of the system as follows:

Table 1. The specification of the 12-bus system.

\begin{tabular}{cc}
\hline Parameter & Value \\
\hline Number of brushes & 11 \\
Number of buses & 12 \\
Minimum voltage at bus & $0.94335 @$ bus 12 \\
Active load (kW) & 435.000 \\
Reactive power (kVAR) & 405.000 \\
Active Power losses (kW) & 20.714 \\
$V D(p . u)$ & 0.4020 \\
$V S I(p . u)$ & 9.4954 \\
\hline
\end{tabular}

Table 2. The cost coefficients and the system constraints.

\begin{tabular}{|c|c|}
\hline Parameter & Value \\
\hline \multicolumn{2}{|l|}{ PV Cost [42] } \\
\hline The purchasing cost of the PV unit $\left(K_{P V}\right)$ & $770 \$ / \mathrm{kW}$ \\
\hline The operation and maintenance costs of the PV unit $\left(K_{P V}^{O \& M}\right)$ & $0.01 \$ / \mathrm{kWh}$ \\
\hline The interest rate of capital investment of the installed PV $\left(\beta_{P V}\right)$ & $10 \%$ \\
\hline The lifetime of the PV unit $\left(N P_{P V}\right)$ & 20 \\
\hline \multicolumn{2}{|l|}{ WT Cost [42] } \\
\hline The purchasing cost of the WT $\left(K_{W T}\right)$ & $4000 \$ / \mathrm{kW}$ \\
\hline $\begin{array}{l}\text { The operation and maintenance costs of the wind turbine } \\
\left(C_{O}^{O \& M}\right)\end{array}$ & $0.01 \$ / \mathrm{kWh}$ \\
\hline The interest rate of capital investment of the installed WT $\left(\beta_{W T}\right)$ & $10 \%$ \\
\hline The lifetime of the WT $\left(N P_{W T}\right)$ & 20 \\
\hline \multicolumn{2}{|l|}{ Cost coefficients } \\
\hline The energy loss cost $\left(K_{\text {Loss }}\right)[43]$ & $0.06 \$ / \mathrm{kWh}$ \\
\hline \multicolumn{2}{|l|}{ Constraints of grid and generators } \\
\hline Voltage limits & 0.95 p.u $\leq V \leq 1.5$ p.u \\
\hline PV sizing limits & $0 \leq P V \leq 435 \mathrm{~kW}$ \\
\hline Wind sizing limits & $0 \leq P_{W} \leq 435 \mathrm{~kW}$ \\
\hline Power factor limits of the WT & $0.65 \leq P . F \leq 1$ \\
\hline
\end{tabular}

Table 3. The selected parameters of the optimization algorithms.

\begin{tabular}{cc}
\hline Parameter Settings & Algorithm \\
\hline EO & $\mathrm{T}_{\max }=100$, Search agents No. $=25$, a $1=2$, a2 $=1, G P=0.5$ \\
WOA & $\mathrm{T}_{\max }=100$, Search agents No. $=25$ \\
SCA & $\mathrm{T}_{\max }=100$, Search agents No. $=25$ \\
\hline
\end{tabular}




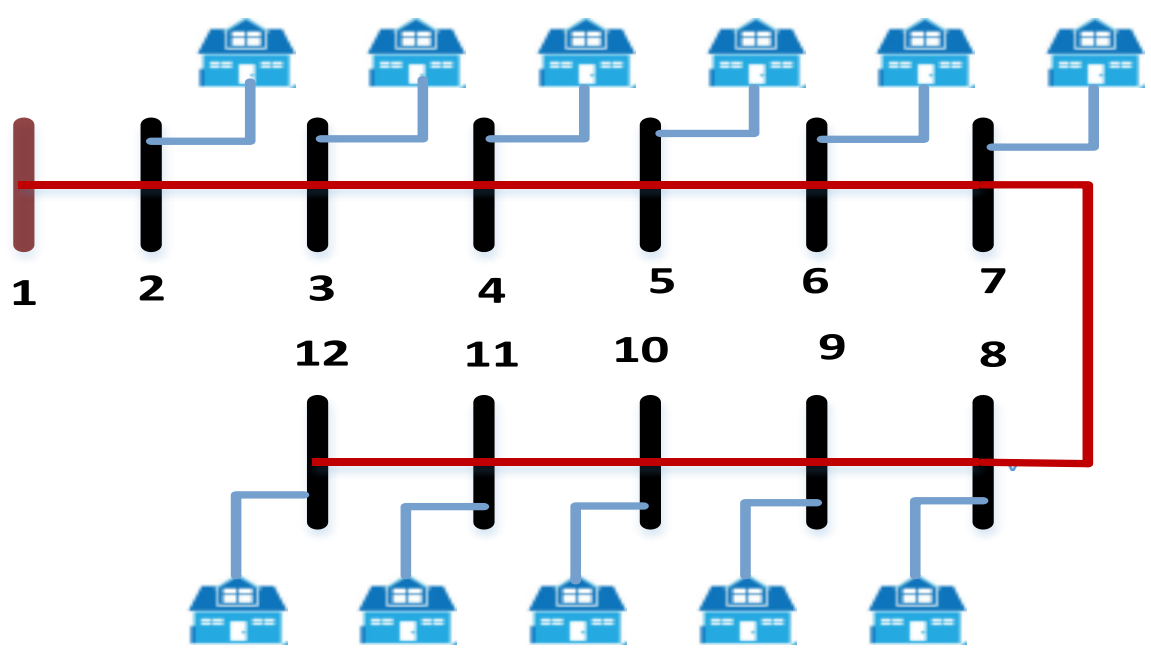

Figure 2. The topology of the studied micro-grid (MG).

\section{Scenario\#1: Energy management under deterministic conditions}

In this case, the proposed algorithm has been applied to solve energy management by considering the variations of the load demand, the wind speed, the solar irradiance, and the market price at deterministic conditions. The hourly load profile is shown in Figure 3. The hourly solar irradiance and the wind speed are depicted in Figures 4 and 5, respectively [44]. The time-varying market price is shown in Figure 6 [45]. Table 4 shows the simulation results for this case by application EO, WOA, and SCA. Without incorporating the RERs, the total cost, the summation of the voltage deviations, and the stability index are $8.56007 \times 10^{5} \$, 7.94398$ p.u., and $2.33983 \times 10^{2}$ p.u., respectively. The voltage profile without incorporating the RERs is shown in Figure 7a. The voltage decreases with increasing the load demand during the day ahead and the minimum voltage magnitude occurs at the 12 th bus.

Judging from Table 4, the obtained results by applying the EO are better than SCA and the WOA in terms of the considered objective functions. By optimal integration of RERs in the MG using EO, the power total cost is reduced to $4.27794 \times 10^{5} \$$, the summation of the voltage deviations is reduced to 3.3260 p.u. and the summation of the voltage stability index is enhanced to $2.515199 \times 10^{2}$ p.u. The optimal sizes and placement of the PV and WT are listed in Table 4. The voltage profiles for this case are depicted in Figure 8. It is clear that the voltage profiles are enhanced considerably with the optimal integration of the RERs.

Furthermore, the power losses are reduced considerably with the inclusion of the RERs as depicted in Figure 8, while the system's stability is significantly enhanced as illustrated in Figure 9. The output powers for the solar PV unit and WT are depicted in Figure 10. According to Figure 10, the output power of the PV unit follows the variations of the solar irradiance, while the yielded power by the WT follows the wind speed variations. The objective function trends with the application of EO, WOA, and SCA are depicted in Figure 11. Referring to this figure, it is evident that EO has a stable convergence characteristic where it converged at the 27th iteration.

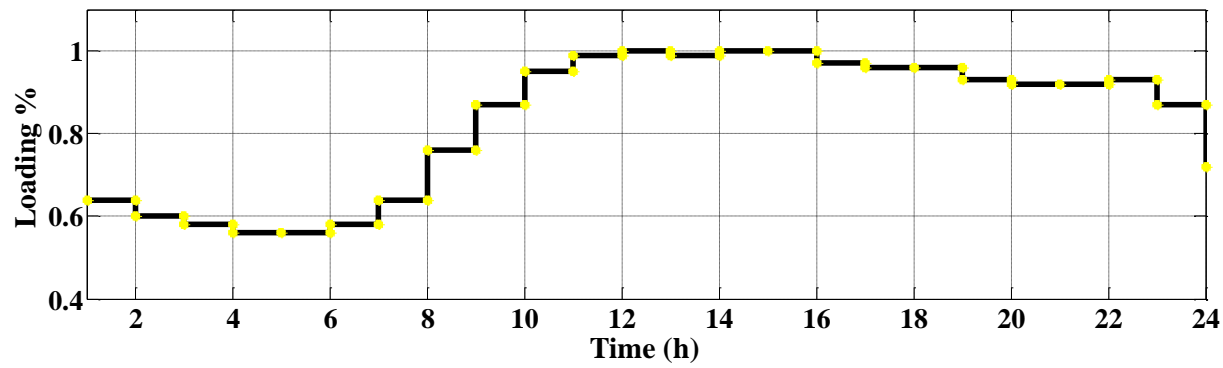

Figure 3. The hourly load profiles. 


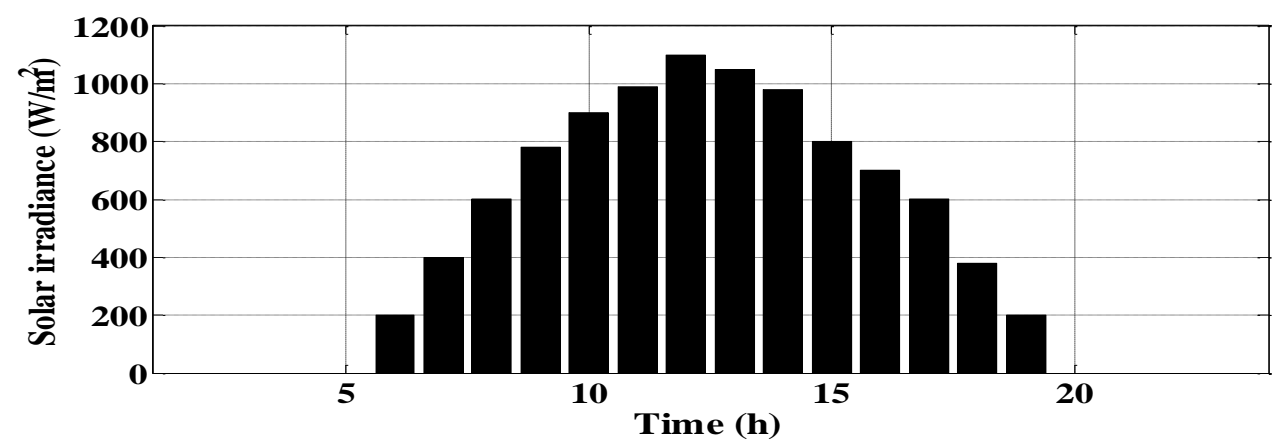

Figure 4. The hourly solar irradiance.

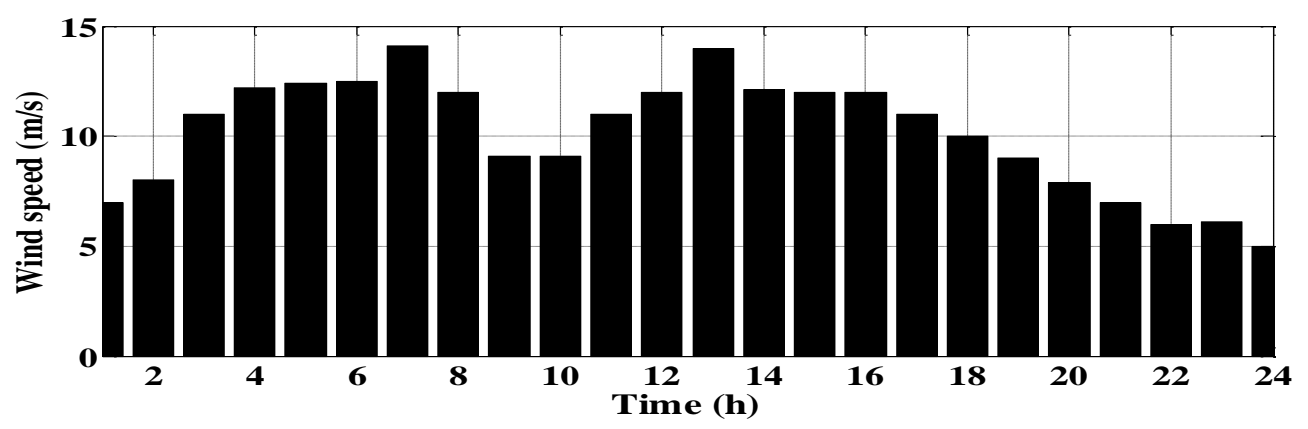

Figure 5. The hourly wind speeds.

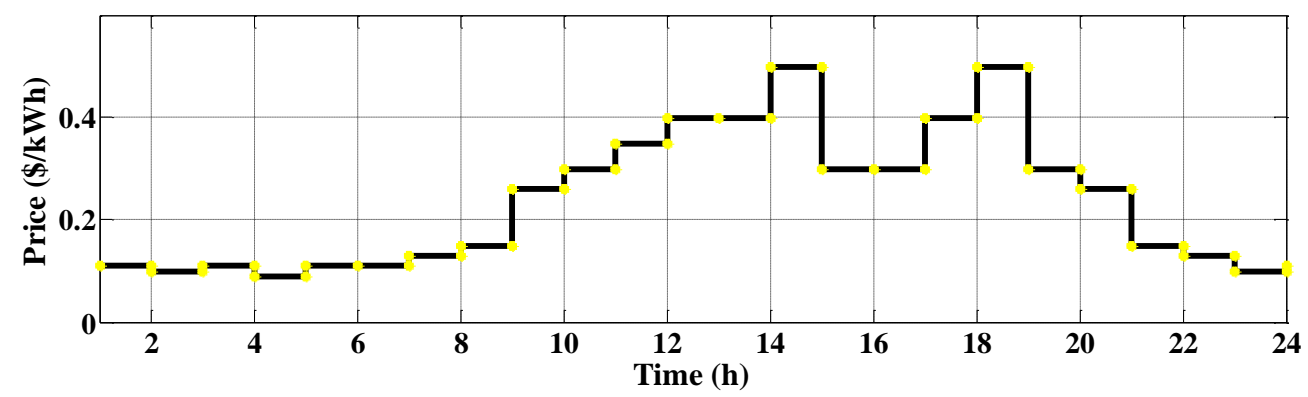

Figure 6. The hourly market price of the upstream grid.

Table 4. The simulation results of energy management of the MG under deterministic conditions.

\begin{tabular}{|c|c|c|c|c|}
\hline & without RERs & EO & WOA & SCA \\
\hline The energy losses (kWh) & $1.2839 \times 10^{5}$ & $7.98140 \times 10^{4}$ & $7.74459 \times 10^{4}$ & $8.22664 \times 10^{4}$ \\
\hline $\begin{array}{l}\text { The purchase energy from } \\
\text { substation }(\mathrm{kWh})\end{array}$ & $3.2880 \times 10^{6}$ & $1.53550 \times 10^{6}$ & $1.44326 \times 10^{6}$ & $1.68776 \times 10^{6}$ \\
\hline $\begin{array}{c}\text { Optimal size (kW) (Location) of the } \\
\text { PV unit }\end{array}$ & - & $297(8)$ & $232(10)$ & $328(8)$ \\
\hline $\begin{array}{l}\text { Optimal size }(\mathrm{kW}) \text { (Location and } \\
\text { power factor (P.F)) of the WT }\end{array}$ & - & $\begin{array}{c}138 \\
(12 \& 0.6858)\end{array}$ & $203(7 \& 0.8714)$ & $85(12 \& 0.9545)$ \\
\hline Cost of energy loss (\$) & $7.70341 \times 10^{3}$ & $4.78884 \times 10^{3}$ & $4.64675 \times 10^{3}$ & $4.93598 \times 10^{3}$ \\
\hline Cost of purchase energy (\$) & $8.48303 \times 10^{5}$ & $3.14267 \times 10^{5}$ & $3.09152 \times 10^{5}$ & $3.43961 \times 10^{4}$ \\
\hline Cost of PV $(\$)$ & - & $3.71928 \times 10^{4}$ & $2.90530 \times 10^{4}$ & $4.10749 \times 10^{4}$ \\
\hline Cost of wind turbine $(\$)$ & - & $7.15460 \times 10^{4}$ & $1.05245 \times 10^{5}$ & $4.40682 \times 10^{4}$ \\
\hline Total cost $(\$)$ & $8.56007 \times 10^{5}$ & $4.27794 \times 10^{5}$ & $4.48097 \times 10^{5}$ & $4.3404 \times 10^{5}$ \\
\hline$\sum V D(p \cdot u)$ & 7.94398 & 3.3260 & 3.5127 & 3.8106 \\
\hline$\sum V S I(p . u)$ & $2.33983 \times 10^{2}$ & 251.5199 & 250.5644 & 249.3393 \\
\hline
\end{tabular}




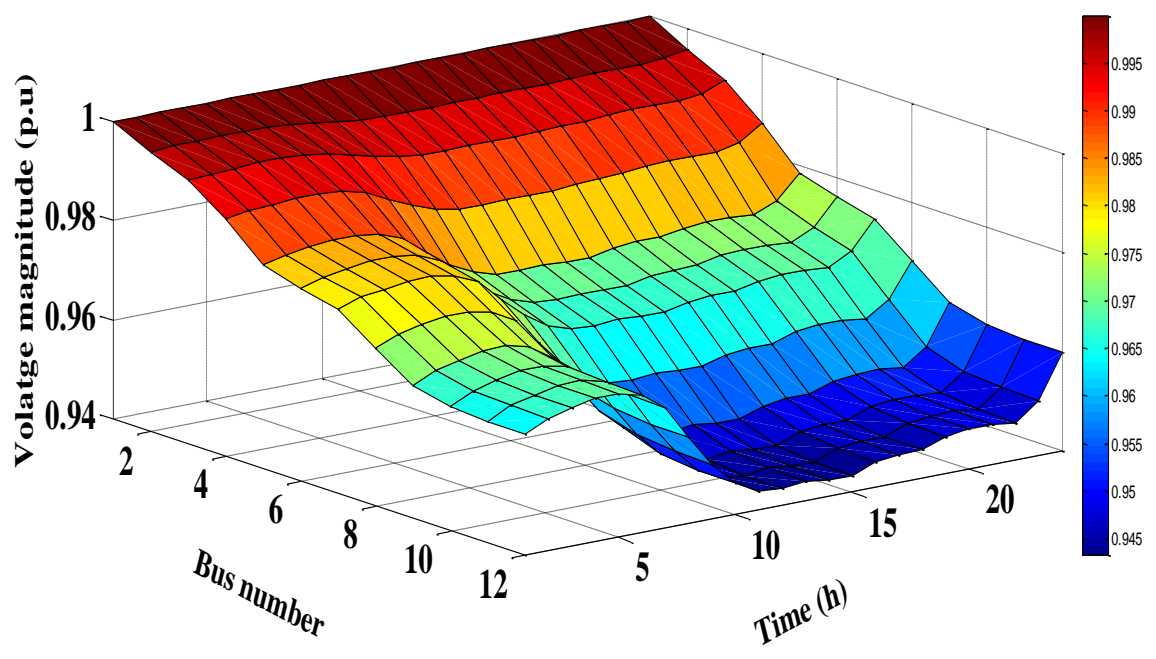

(a)

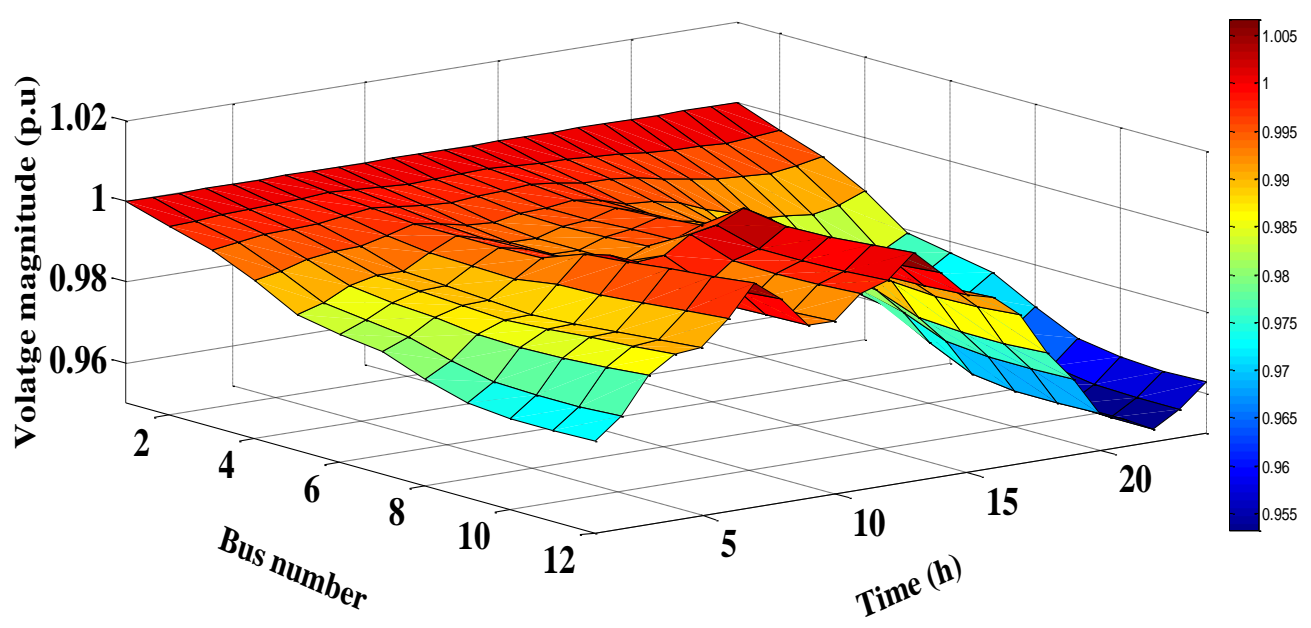

(b)

Figure 7. The voltage profile (a) without RERs, (b) With RERs.

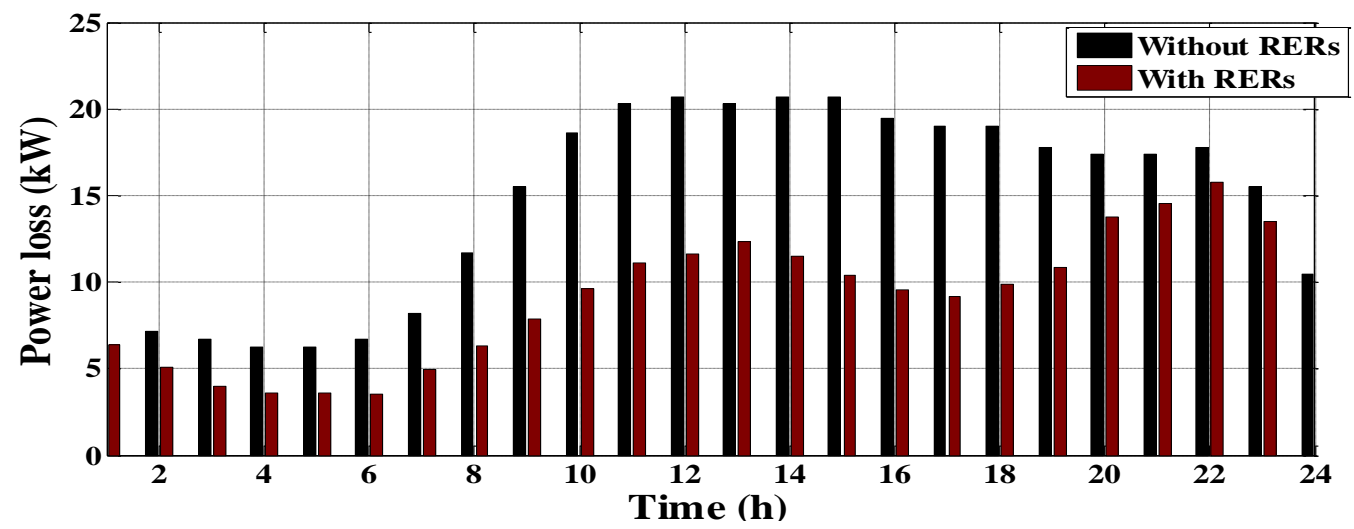

Figure 8. Power losses with and without RERs. 


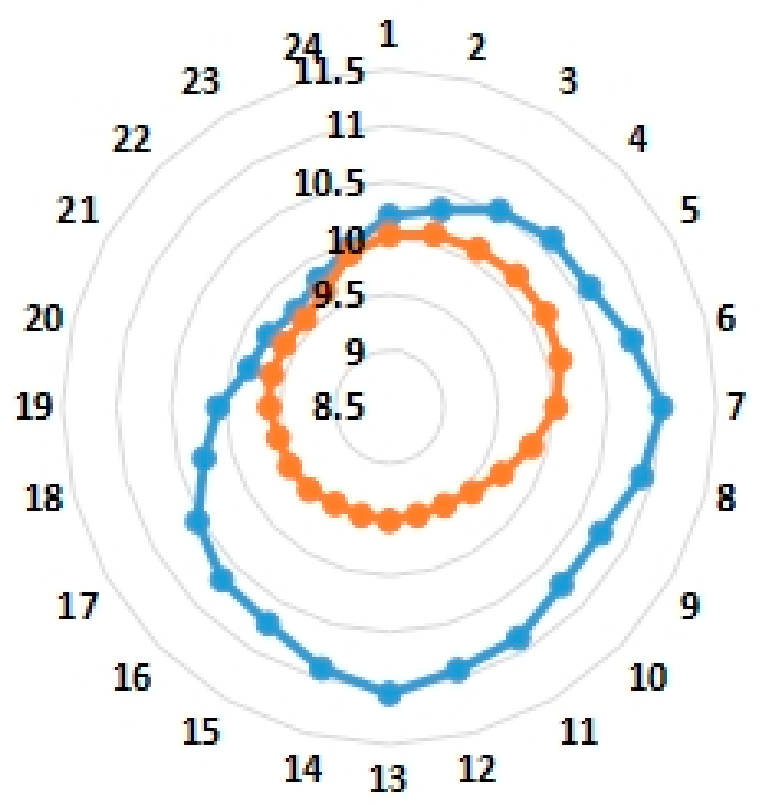

\section{$\longrightarrow$ With RERs - Without RERs}

Figure 9. Summation of the voltage stability index with and without RERs.

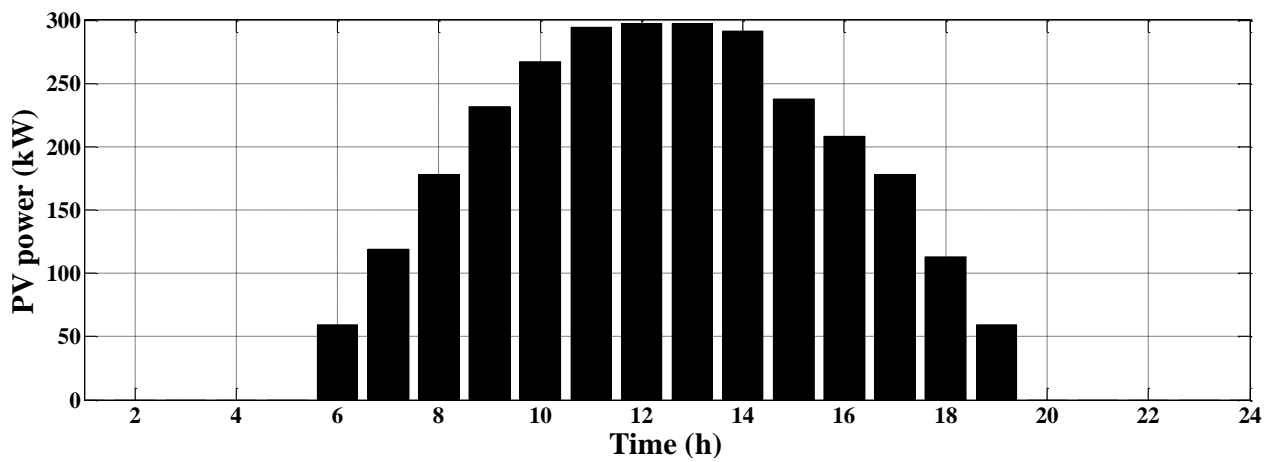

(a)

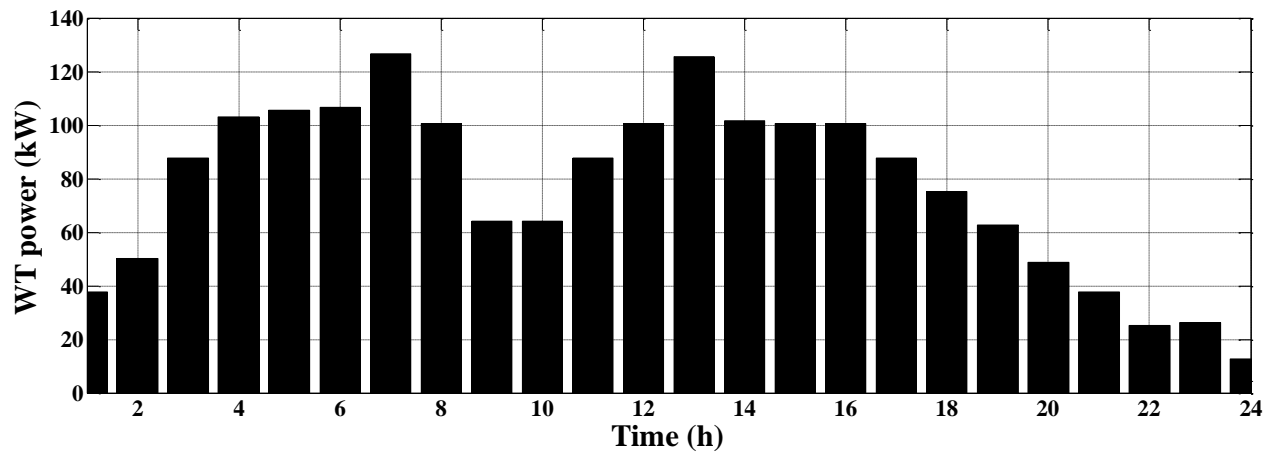

(b)

Figure 10. The hourly output power of RERs (a) photovoltaic (PV) unit, (b) wind turbine (WT). 


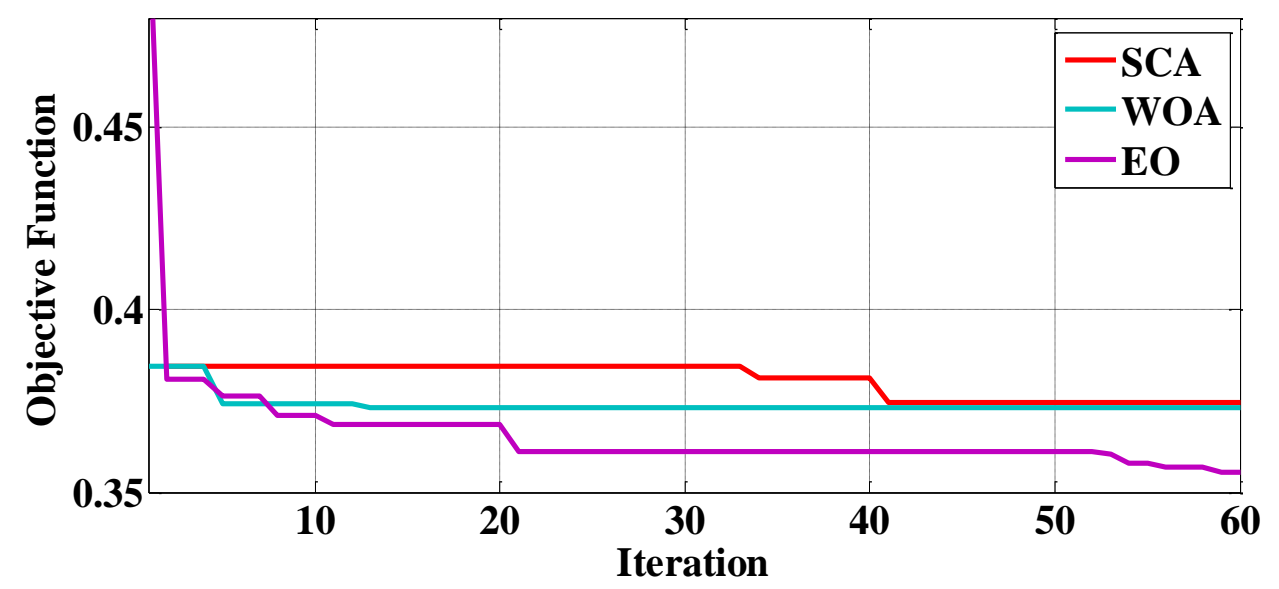

Figure 11. Objective function for sine cosine algorithm (SCA), whale optimization algorithm (WOA), and EO.

Scenario\#2: Energy management under probabilistic conditions

In this section, the MG's energy management is solved under probabilistic conditions where the uncertainties of the load demand, wind speed, and solar irradiance have been considered. Three years of hourly historical data of load demand, solar irradiance, and wind speed have been considered in this paper. The obtained load profile, solar irradiance, and the wind speed are depicted in Figures 12-14, respectively. Table 5 shows the captured results for optimal energy management by application the EO technique with and without inclusion RERs. Without integrating the RERs under the uncertainties of load demand, the total cost, summation of the voltage deviations, and the stability index are $8.87522 \times 10^{5} \$, 8.57474$ p.u., and $2.31695 \times 10^{2}$ p.u., respectively. With optimal integration of the RERs, the total cost and summation of the voltage deviations is reduced to $4.76101 \times 10^{5} \$ 4.15795$ p.u.; at the same time, the summation of the voltage stability index is improved to be $2.49093 \times 10^{2}$ p.u. The optimal location and rating of the PV and WT are also listed in Table 5. Figure 15 shows the voltage profile with and without the inclusion RERs. Judging from this figure, the voltage profile is enhanced by optimal energy management with RERs.

Furthermore, the power loss is reduced considerably with the inclusion of the RERs as depicted in Figure 16. In addition, the voltage stability index also improved during the day ahead, according to Figure 17. The output powers of the PV and WT at probabilistic conditions are depicted in Figure 18. The output power of the PV unit is varied with the variation of the forecasting of the solar irradiance, while the output power of the WT follows the forecasting of the wind speed.

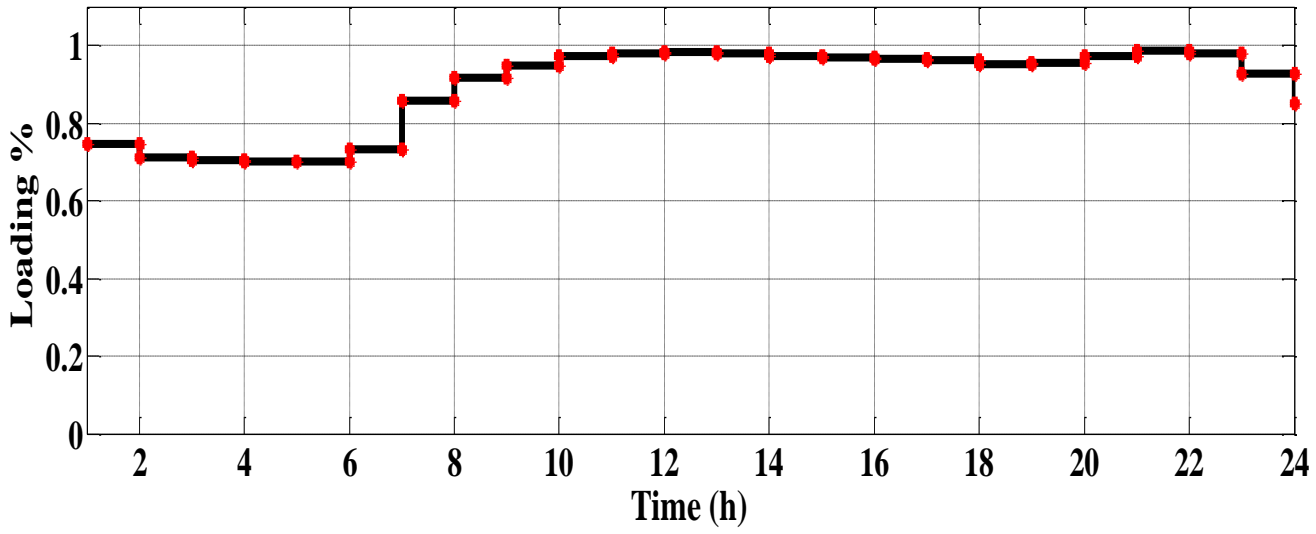

Figure 12. The forecasting load profile. 


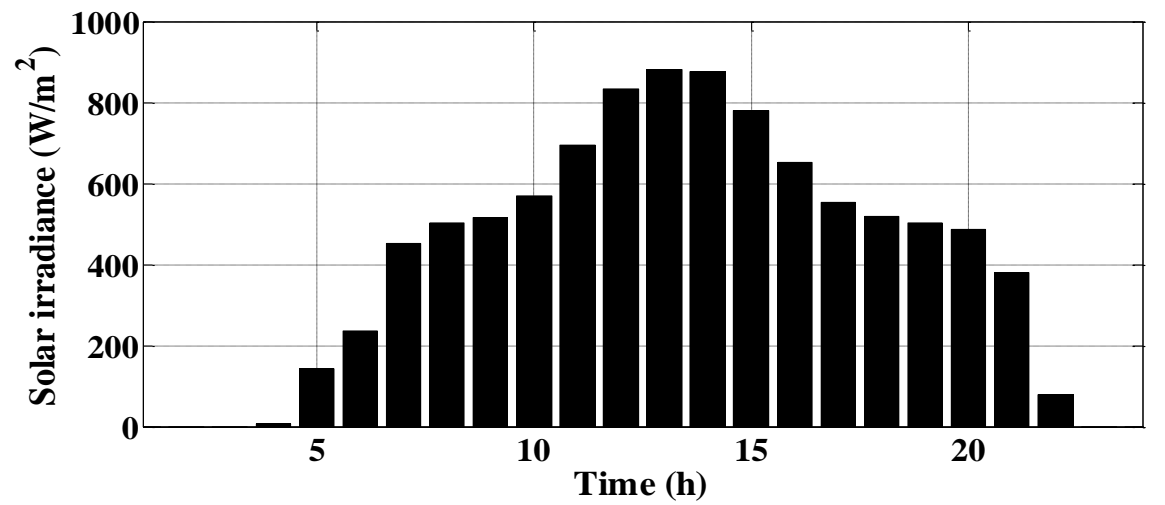

Figure 13. The forecasting solar irradiance.

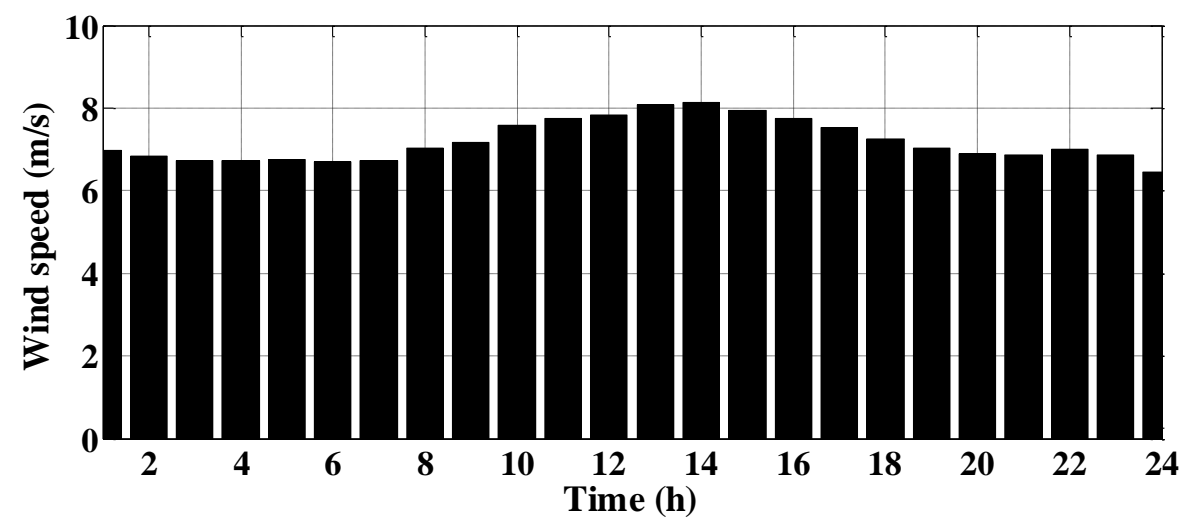

Figure 14. The forecasting wind speed.

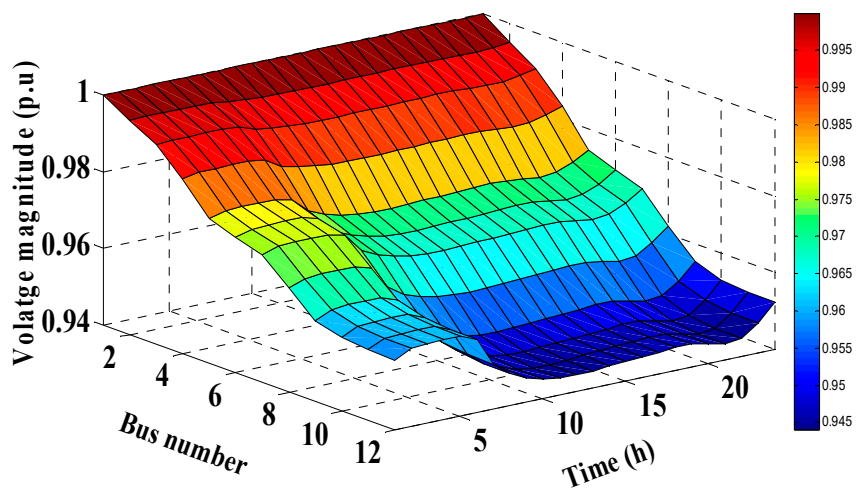

(a)

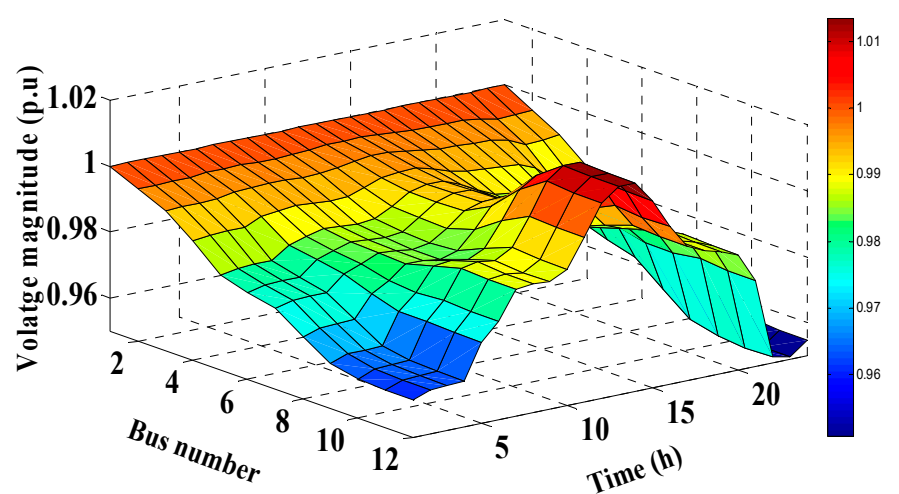

(b)

Figure 15. The voltage profile under probabilistic conditions (a) without RERs, (b) with RERs. 
Table 5. The simulation results of energy management of the MG under probabilistic conditions.

\begin{tabular}{ccc}
\hline & without RERs & With RERs \\
\hline The energy losses (kWh) & $1.45699 \times 10^{5}$ & $9.68580 \times 10^{4}$ \\
The purchase energy from substation (kWh) & $3.54878 \times 10^{6}$ & $2.01951 \times 10^{6}$ \\
Optimal size (kW) (Location) of the PV unit & 0 & $385(10)$ \\
Optimal size (kW) (Location \& P.F) of the WT & 0 & $50(12 \& 0.8039)$ \\
Cost of energy loss (\$) & $8.74194 \times 10^{3}$ & $5.81148 \times 10^{3}$ \\
Cost of purchase energy (\$) & $3.54878 \times 10^{6}$ & $2.01951 \times 10^{6}$ \\
Cost of PV (\$) & 0 & $4.83546 \times 10^{4}$ \\
Cost of wind turbine (\$) & 0 & $2.47624 \times 10^{4}$ \\
Total cost (\$) & $8.87522 \times 10^{5}$ & $4.76101 \times 10^{5}$ \\
$\sum V D(p . u)$ & 8.57474 & 4.15795 \\
$\sum V S I(p . u)$ & $2.31695 \times 10^{2}$ & $2.49093 \times 10^{2}$ \\
\hline
\end{tabular}

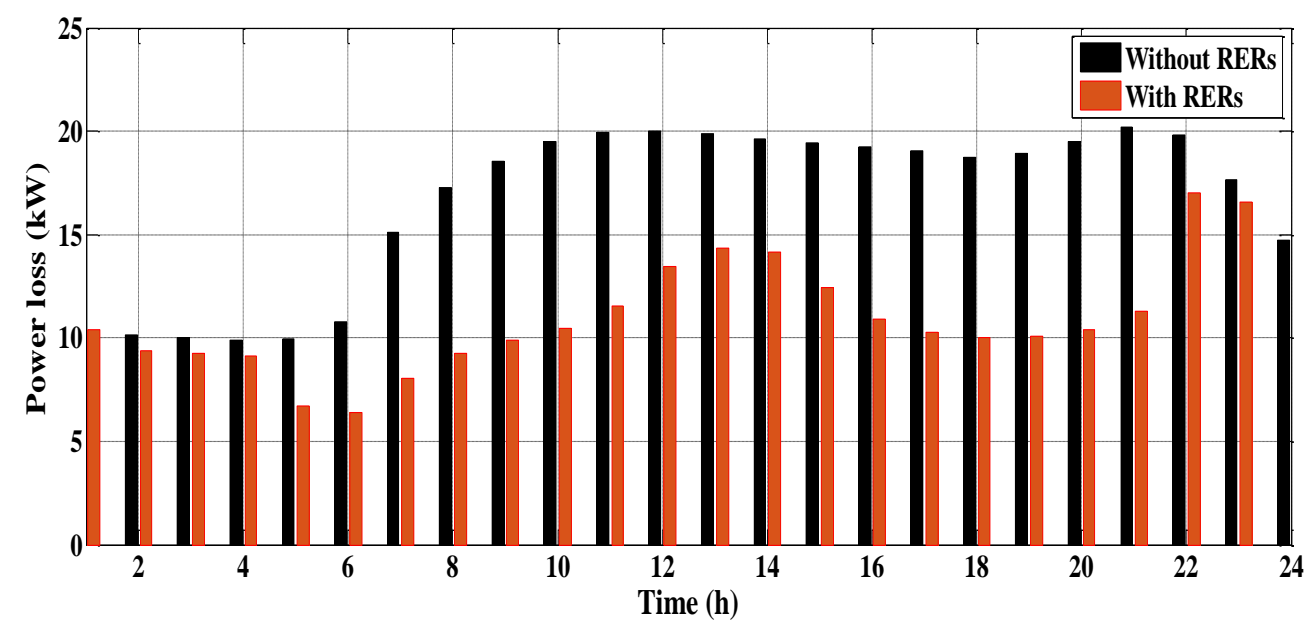

Figure 16. The power losses considering the uncertainties of the system.

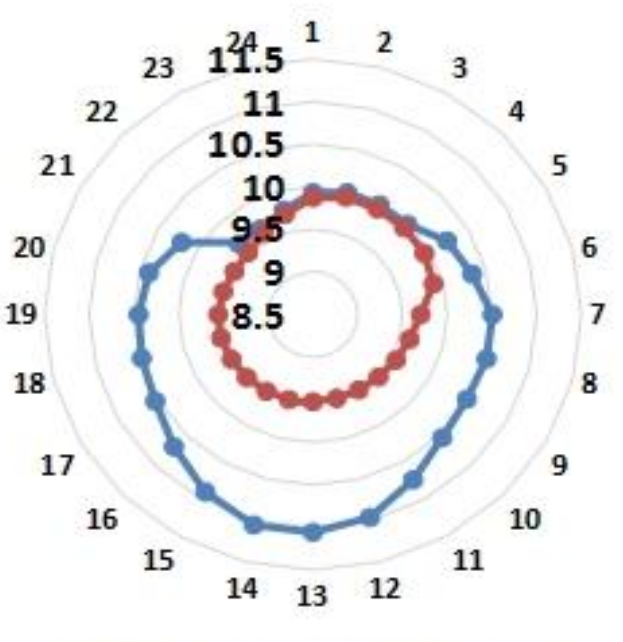

- With RERS - Without RERs

Figure 17. Voltage stability index at the uncertainties of system. 


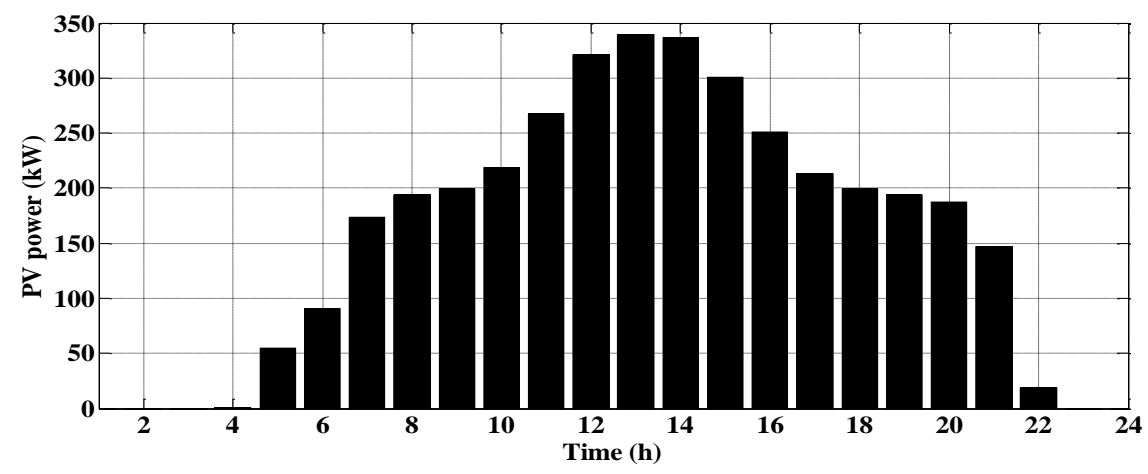

(a)

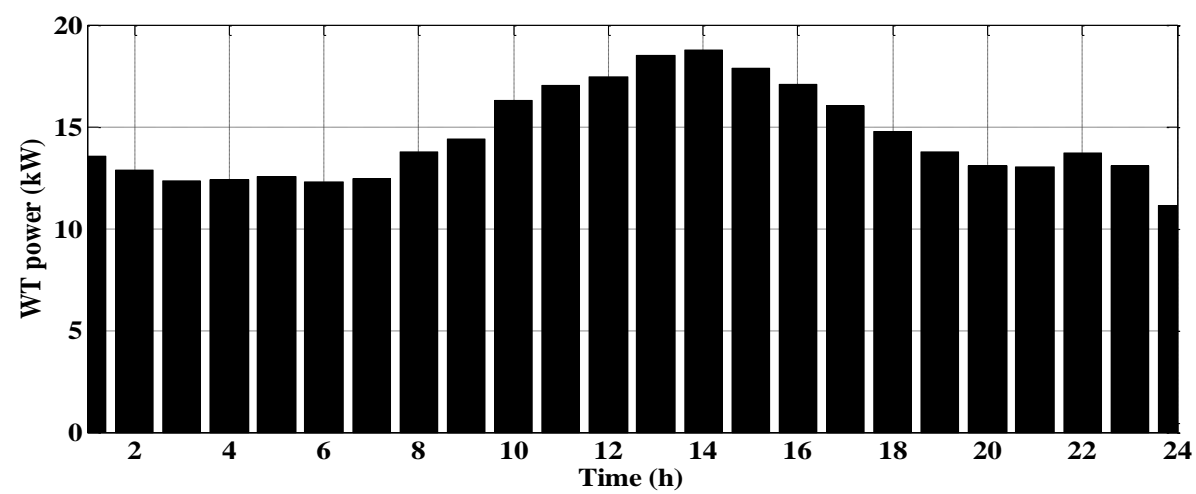

(b)

Figure 18. The hourly output power under uncertainty condition of RERs (a) PV unit, (b) WT.

\section{Conclusions}

In this paper, micro-grid's energy management problem has been solved with the optimal integration of solar PV and wind turbine. An efficient optimization technique known as equilibrium optimizer (EO) has been applied considering the variations of load demand, wind speed, solar irradiance, and market price under deterministic and probabilistic conditions. The proposed algorithm for energy management has been validated on 12 bus micro-grid systems for cost reduction, voltage profile, and stability improvement simultaneously. The obtained results by EO have been compared with two optimization techniques (WOA, SCA). The paper's conclusions can be summarized as follows:

- The proposed EO algorithm is an effective algorithm for solving the energy management problem of MG under deterministic and probabilistic conditions.

- $\quad$ The proposed EO algorithm has been successfully assigned the optimal locations and ratings of the RERs for optimal energy management.

- Under the deterministic condition, solving the energy management with optimal integration of the RERs can reduce the total cost and decrease the voltage deviations by $50.02 \%$ and $58.13 \%$, respectively. At the same time, summation the voltage stability index is enhanced by $7.4949 \%$.

- Under the probabilistic condition, solving the energy management with optimal integration of the RERs can reduce the total cost and decrease the voltage deviations by $46.36 \%$ and $51.51 \%$, respectively. At the same time, summation the voltage stability index is enhanced by $7.51 \%$.

- The proposed EO algorithm has stable convergence characteristics and it is superior for solving the MG's energy management compared with SCA and WOA.

- The obtained results by application of the EO are better than compared with the reported algorithms in terms of the considered objective function where the total cost has been reduced by $4.746 \%$ and $1.460 \%$ compared with WOA and SCA, respectively. 
in addition of that $\sum V D$ has been minimized by $5.315 \%$ and $12.717 \%$ compared with WOA and SCA while $\sum$ VSI has been enhance by $0.3813 \%$ and $0.8746 \%$ compared with WOA and SCA, respectively.

Author Contributions: Conceptualization, D.A. and M.E.; data curation, A.A. and S.K.; formal analysis, A.S.A.; resources, A.A. and A.S.A.; methodology, D.A. and S.K.; software, D.A. and M.E.; supervision, A.S.A.; validation, D.A. and M.E.; visualization, A.A. and S.K.; writing-original draft, D.A. and M.E.; writing—review and editing, A.A., A.S.A., and S.K. All authors together organized and refined the manuscript into the present form. All authors have approved the final version of the submitted paper. All authors have read and agreed to the published version of the manuscript.

Funding: This research was supported by the Deanship of Scientific Research at Majmaah University under Project Number No (R-2021-12).

Acknowledgments: The authors extend their appreciation to the Deanship of Scientific Research at Majmaah University for funding this work under Project Number No (R-2021-12).

Conflicts of Interest: The authors declare no conflict of interest.

\section{Nomenclature}

\begin{tabular}{|c|c|}
\hline Acronyms & \\
\hline PV & Photovoltaic \\
\hline WT & Wind turbine \\
\hline SCA & Sine cosine algorithm \\
\hline WOA & Whale optimization algorithm \\
\hline $\mathrm{EO}$ & Equilibrium equalizer \\
\hline DGs & Distributed generators \\
\hline MG & Micro-grid \\
\hline MOPSO & Multi-objective particle swarm optimization \\
\hline MBFO & Bacterial foraging optimization \\
\hline $\mathrm{CHP}$ & Combined heat and power \\
\hline FSAPSO & Fuzzy self-adaptive particle swarm optimization \\
\hline MHBMO & Modified honeybee mating optimization \\
\hline ESSA & Efficient salp swarm algorithm \\
\hline ALO & Ant-lion optimizer \\
\hline SOS & Symbiotic organisms search \\
\hline MFO & Moth flame optimization \\
\hline RESs & Renewable resources \\
\hline pdf & Probability distribution function \\
\hline GP & Generation probability \\
\hline P.F & Power factor \\
\hline$C F$ & Capital recovery factor \\
\hline$V S I$ & Voltage stability factor \\
\hline$N B$ & Number of buses \\
\hline VD & Voltage deviation \\
\hline $\mathrm{V}$ & Control volume \\
\hline Q & Flow rate \\
\hline MFA & Modified firefly algorithm \\
\hline Indices an & \\
\hline $\mathrm{Co}_{\text {Grid }}$ & Cost of purchasing electric energy from the main substation \\
\hline$P_{\text {Grid }(h)}$ & Hourly power \\
\hline $\mathrm{Co}_{\text {loss }}$ & Annual loss cost \\
\hline Cost $t_{P V}^{\text {inst. }}$ & Installment cost of PV \\
\hline $\operatorname{Cost}_{P V}^{O \& M}$ & Operation and maintenance cost of PV \\
\hline$P_{P V(h)}$ & PV hourly power \\
\hline Psr & PV rated power \\
\hline$P_{r}$ & Rated output power of the wind turbine \\
\hline$\omega_{r}$ & Rated wind speed \\
\hline
\end{tabular}




\begin{tabular}{|c|c|}
\hline$V_{n}$ & Nominal voltage \\
\hline$W_{1}, W_{2}, W_{3}$ & The weight factors \\
\hline$P_{\text {loss DGs }}$ & DGs power loss \\
\hline$P_{\text {loss Base }}$ & Loss power base \\
\hline$V D_{D G s}$ & Voltage deviation of DGs \\
\hline$V D_{\text {base }}$ & Voltage deviation base \\
\hline$C R F$ & Capital recovery factor \\
\hline$C_{P V}$ & Investment cost of PV \\
\hline$C_{W T}$ & Investment cost of WT \\
\hline Pwt & WT rated power \\
\hline$i_{r t}$ & Internal rate \\
\hline$n$ & Number of years \\
\hline$G_{S}$ & Solar irradiance \\
\hline$G_{s t d}$ & $1000 \mathrm{~W} / \mathrm{m}^{2}$ \\
\hline$X_{c}$ & Represents a certain irradiance point \\
\hline$\omega_{0}$ & Cut-out wind speed \\
\hline$\omega_{i}$ & Denotes the cut-in wind speed \\
\hline $\operatorname{Cost}_{D G s}$ & Total cost of DGs \\
\hline Cost $_{\text {base }}$ & Total cost base \\
\hline$V S I$ & Voltage stability index \\
\hline$T_{\max }$ & Number of iterations \\
\hline Cost ${ }_{P V}^{\text {inst. }}$ & Installation cost of the PV \\
\hline $\mathrm{Co}_{P V}^{O \& M}$ & Operation and maintenance costs of the PV unit \\
\hline Cost ${ }_{W T}^{\text {inst. }}$ & Installation cost of the WT \\
\hline $\mathrm{Co}_{W T}^{O \& M}$ & Operation and maintenance costs of the wind turbine \\
\hline$N P$ & Lifetime of the PV unit or the WT \\
\hline \multicolumn{2}{|c|}{ Parameters and Constants } \\
\hline$G_{S}$ & Irradiance \\
\hline$X_{c}$ & A certain irradiance point \\
\hline$G_{S T D}$ & Standard environment solar irradiance \\
\hline$P_{\text {loss DGs }}$ & The power losses with inclsion DG \\
\hline$V_{n}$ & Voltage of the $n^{\text {th }}$ bus \\
\hline$R_{n m}$ & Resistance of the transmission line between buses $m$ and $n$ \\
\hline$X_{n m}$ & Reactance of the transmission line between buses $m$ and $n$ \\
\hline$I_{n}$ & Current at the $\mathrm{n}$-th branch \\
\hline$\Gamma$ & Gamma function \\
\hline$\alpha, \beta$ & Beta parameters for each period \\
\hline$\mu$ & Mean deviation of the solar irradiance for each time segment \\
\hline$c$ & Scale parameter of Rayleigh \\
\hline$\sigma$ & Standard deviation of the solar irradiance for each time segment \\
\hline \multicolumn{2}{|c|}{ Variables and Functions } \\
\hline$F$ & Multi-objective function \\
\hline$f_{1}$ & The objective function representing the active total power losses \\
\hline$f_{2}$ & The objective function representing total voltage drop \\
\hline$f_{3}$ & The objective function representing the overall voltage stability index \\
\hline$K_{\text {Grid }}$ & Purchasing energy cost from the grid \\
\hline$K_{\text {Loss }}$ & Energy loss cost \\
\hline$K_{P V}^{O \& M}$ & The operation and maintenance costs of the PV unit \\
\hline$K_{W T}$ & The purchasing cost of the WT \\
\hline$K_{P V}$ & The purchasing cost of the PV \\
\hline
\end{tabular}


Appendix A

Table A1. The data bus and line data of the 12-bus system.

\begin{tabular}{ccccccc}
\hline Branch No. & Send Bus & Receive Bus & $\mathbf{R}(\mathbf{o h m})$ & $\mathbf{X}(\mathbf{o h m})$ & $\boldsymbol{P}_{\boldsymbol{D}}(\mathbf{k W})$ & $\boldsymbol{Q}_{\boldsymbol{D}}(\mathbf{k V A R})$ \\
\hline 1 & 1 & 2 & 1.093 & 0.455 & 60 & 60 \\
2 & 2 & 3 & 1.184 & 0.494 & 40 & 30 \\
3 & 3 & 4 & 2.095 & 0.873 & 55 & 55 \\
4 & 4 & 5 & 3.188 & 1.329 & 30 & 30 \\
5 & 5 & 6 & 1.093 & 0.455 & 20 & 15 \\
6 & 6 & 7 & 1.002 & 0.417 & 55 & 55 \\
7 & 7 & 8 & 4.403 & 1.215 & 45 & 45 \\
8 & 8 & 9 & 5.642 & 1.597 & 40 & 40 \\
10 & 9 & 10 & 2.89 & 0.818 & 35 & 30 \\
11 & 10 & 11 & 1.514 & 0.428 & 40 & 15 \\
\hline
\end{tabular}

\section{References}

1. Akorede, M.F.; Hizam, H.; Pouresmaeil, E. Distributed energy resources and benefits to the environment. Renew. Sustain. Energy Rev. 2010, 14, 724-734. [CrossRef]

2. Riaz, M.; Awan, M.A.I.; Khalil, L.; Mushtaq, I.; Bhatti, K.L.; Siddique, M. Economically efficient, environment friendly \& power stack shed reduction energy management system by utilizing renewable energy resources for remote hilly areas of Pakistan. Mater. Today Proc. 2020, 9, 1-5.

3. Hong, B.; Miao, W.; Liu, Z.; Wang, L. Architecture and Functions of Micro-grid Energy Management System for the Smart Distribution Network Application. Energy Procedia 2018, 145, 478-483. [CrossRef]

4. Adefarati, T.; Bansal, R.C. Reliability, economic and environmental analysis of a microgrid system in the presence of renewable energy resources. Appl. Energy 2019, 236, 1089-1114. [CrossRef]

5. Mazidi, M.; Zakariazadeh, A.; Jadid, S.; Siano, P. Integrated scheduling of renewable generation and demand response programs in a microgrid. Energy Convers. Manag. 2014, 86, 1118-1127. [CrossRef]

6. Kamel, R.M. Effect of wind generation system types on Micro-Grid (MG) fault performance during both standalone and grid connected modes. Energy Convers. Manag. 2014, 79, 232-245. [CrossRef]

7. Kamel, R.M.; Nagasaka, K. Effect of load type on standalone micro grid fault performance. Appl. Energy 2015, 160, 532-540. [CrossRef]

8. Dawoud, S.M.; Lin, X.; Okba, M.I. Hybrid renewable microgrid optimization techniques: A review. Renew. Sustain. Energy Rev. 2018, 82, 2039-2052. [CrossRef]

9. Aghajani, G.; Ghadimi, N. Multi-objective energy management in a micro-grid. Energy Rep. 2018, 4, 218-225. [CrossRef]

10. Motevasel, M.; Seifi, A.R. Expert energy management of a micro-grid considering wind energy uncertainty. Energy Convers. Manag. 2014, 83, 58-72. [CrossRef]

11. Motevasel, M.; Seifi, A.R.; Niknam, T. Multi-objective energy management of CHP (combined heat and power)-based micro-grid. Energy 2013, 51, 123-136. [CrossRef]

12. Moghaddam, A.A.; Seifi, A.; Niknam, T. Multi-operation management of a typical micro-grids using Particle Swarm Optimization: A comparative study. Renew. Sustain. Energy Rev. 2012, 16, 1268-1281. [CrossRef]

13. Wu, L.Z.; Hao, X.H. Multi-objective operation optimization of a micro-grid using modified honey bee mating optimization algorithm. Appl. Mech. Mater. 2014, 494-495, 1593-1597. [CrossRef]

14. Elattar, E.E.; ElSayed, S.K. Probabilistic energy management with emission of renewable micro-grids including storage devices based on efficient salp swarm algorithm. Renew. Energy 2020, 153, 23-35. [CrossRef]

15. Roy, K.; Mandal, K.K.; Mandal, A.C. Ant-Lion Optimizer algorithm and recurrent neural network for energy management of micro grid connected system. Energy 2019, 167, 402-416. [CrossRef]

16. Kamel, S.; Ramadan, A.; Ebeed, M.; Nasrat, L.; Ahmed, M.H. Sizing and Evaluation Analysis of Hybrid Solar-Wind Distributed Generations in Real Distribution Network Considering the Uncertainty. In Proceedings of the 2019 International Conference on Computer, Control, Electrical, and Electronics Engineering (ICCCEEE), Khartoum, Sudan, 21-23 September 2019; pp. 1-5.

17. Kamankesh, H.; Agelidis, V.G.; Kavousi-Fard, A. Optimal scheduling of renewable micro-grids considering plug-in hybrid electric vehicle charging demand. Energy 2016, 100, 285-297. [CrossRef]

18. Zolfaghari, M.; Ghaffarzadeh, N.; Ardakani, A.J. Optimal sizing of battery energy storage systems in off-grid micro grids using convex optimization. J. Energy Storage 2019, 23, 44-56. [CrossRef]

19. Mohseni, S.; Brent, A.C.; Burmester, D. A demand response-centred approach to the long-term equipment capacity planning of grid-independent micro-grids optimized by the moth-flame optimization algorithm. Energy Convers. Manag. 2019, $200,112105$. [CrossRef] 
20. Faramarzi, A.; Heidarinejad, M.; Stephens, B.; Mirjalili, S. Equilibrium optimizer: A novel optimization algorithm. Knowl. Based Syst. 2020, 191, 105190. [CrossRef]

21. Özkaya, H.; Yıldız, M.; Yıldız, A.R.; Bureerat, S.; Yıldız, B.S.; Sait, S.M. The equilibrium optimization algorithm and the response surface-based metamodel for optimal structural design of vehicle components. Mater. Test. 2020, 62, 492-496. [CrossRef]

22. Abdul-hamied, D.T.; Shaheen, A.M.; Salem, W.A.; Gabr, W.I.; El-sehiemy, R.A. Equilibrium optimizer based multi dimensions operation of hybrid AC/DC grids. Alex. Eng. J. 2020, 59, 4787-4803. [CrossRef]

23. Abdel-Basset, M.; Chang, V.; Mohamed, R. A novel equilibrium optimization algorithm for multi-thresholding image segmentation problems. Neural Comput. Appl. 2020, 1-34. [CrossRef]

24. Shaheen, A.; Elsayed, A.; El-Sehiemy, R.A.; Abdelaziz, A.Y. Equilibrium optimization algorithm for network reconfiguration and distributed generation allocation in power systems. Appl. Soft Comput. 2021, 98, 106867. [CrossRef]

25. Gao, Y.; Zhou, Y.; Luo, Q. An Efficient Binary Equilibrium Optimizer Algorithm for Feature Selection. IEEE Access 2020, 8 , 140936-140963. [CrossRef]

26. Ramadan, A.; Ebeed, M.; Kamel, S.; Nasrat, L. Optimal power flow for distribution systems with uncertainty. In Uncertainties in Modern Power Systems; Elsevier: Amsterdam, The Netherlands, 2020; pp. 145-162.

27. EI-Bidairi, K.S.; Nguyen, H.D.; Jayasinghe, S.; Mahmoud, T.S. Multiobjective intelligent energy management optimization for grid-connected microgrids. In Proceedings of the 2018 IEEE International Conference on Environment and Electrical Engineering and 2018 IEEE Industrial and Commercial Power Systems Europe (EEEIC/I\&CPS Europe), Palermo, Italy, 12-15 June 2018; pp. 1-6.

28. Mahmud, K.; Sahoo, A. Multistage energy management system using autoregressive moving average and artificial neural network for day-ahead peak shaving. Electron. Lett. 2019, 55, 853-855. [CrossRef]

29. Khan, M.W.; Wang, J.; Xiong, L. Optimal energy scheduling strategy for multi-energy generation grid using multi-agent systems. Int. J. Electr. Power Energy Syst. 2021, 124, 106400. [CrossRef]

30. Divakaran, A.M.; Hamilton, D.; Manjunatha, K.N.; Minakshi, M. Design, development and thermal analysis of reusable Li-ion battery module for future mobile and stationary applications. Energies 2020, 13, 1477. [CrossRef]

31. Sundaram, M.M.; Appadoo, D. Traditional salt-in-water electrolyte vs. water-in-salt electrolyte with binary metal oxide for symmetric supercapacitors: Capacitive vs. faradaic. Dalton Trans. 2020, 49, 11743-11755. [CrossRef]

32. Minakshi, M.; Mitchell, D.R.; Jones, R.T.; Pramanik, N.C.; Jean-Fulcrand, A.; Garnweitner, G. A hybrid electrochemical energy storage device using sustainable electrode materials. ChemistrySelect 2020, 5, 1597-1606. [CrossRef]

33. Ebeed, M.; Aleem, S.H.A. Overview of uncertainties in modern power systems: Uncertainty models and methods. In Uncertainties in Modern Power Systems; Elsevier: Amsterdam, The Netherlands, 2020; pp. 1-34.

34. Moradi, M.; Abedini, M. A combination of genetic algorithm and particle swarm optimization for optimal distributed generation location and sizing in distribution systems with fuzzy optimal theory. Int. J. Green Energy 2012, 9, 641-660. [CrossRef]

35. Ali, E.; Abd Elazim, S.; Abdelaziz, A.J.E. Ant lion optimization algorithm for renewable distributed generations. Energy 2016, 116, 445-458. [CrossRef]

36. Akbari, M.A.; Aghaei, J.; Barani, M.; Savaghebi, M.; Shafie-Khah, M.; Guerrero, J.M.; Catalao, J.P. New metrics for evaluating technical benefits and risks of DGs increasing penetration. IEEE Trans. Smart Grid 2017, 8, 2890-2902. [CrossRef]

37. Ali, A.; Raisz, D.; Mahmoud, K.; Lehtonen, M. Optimal placement and sizing of uncertain PVs considering stochastic nature of PEVs. IEEE Trans. Sustain. Energy 2019, 11, 1647-1656. [CrossRef]

38. Ebeed, M.; Ali, A.; Mosaad, M.I.; Kamel, S. An Improved Lightning Attachment Procedure Optimizer for Optimal Reactive Power Dispatch With Uncertainty in Renewable Energy Resources. IEEE Access 2020, 8, 168721-168731. [CrossRef]

39. Zubo, R.H.; Mokryani, G.; Abd-Alhameed, R. Optimal operation of distribution networks with high penetration of wind and solar power within a joint active and reactive distribution market environment. Appl. Energy 2018, 220, 713-722. [CrossRef]

40. Atwa, Y.; El-Saadany, E.; Salama, M.; Seethapathy, R. Optimal renewable resources mix for distribution system energy loss minimization. IEEE Trans. Power Syst. 2009, 25, 360-370. [CrossRef]

41. Soroudi, A. Possibilistic-scenario model for DG impact assessment on distribution networks in an uncertain environment. IEEE Trans. Power Syst. 2012, 27, 1283-1293. [CrossRef]

42. Gampa, S.R.; Das, D. Optimum placement and sizing of DGs considering average hourly variations of load. Int. J. Electr. Power Energy Syst. 2015, 66, 25-40. [CrossRef]

43. Sultana, S.; Roy, P.K. Optimal capacitor placement in radial distribution systems using teaching learning based optimization. Int. J. Electr. Power Energy Syst. 2014, 54, 387-398. [CrossRef]

44. Moradi, M.H.; Abedini, M.; Tousi, S.R.; Hosseinian, S.M. Optimal siting and sizing of renewable energy sources and charging stations simultaneously based on Differential Evolution algorithm. Int. J. Electr. Power Energy Syst. 2015, 73, 1015-1024. [CrossRef]

45. Zhang, Y.; Ren, S.; Dong, Z.Y.; Xu, Y.; Meng, K.; Zheng, Y. Optimal placement of battery energy storage in distribution networks considering conservation voltage reduction and stochastic load composition. IET Gener. Transm. Distrib. 2017, 11, 3862-3870. [CrossRef] 